- Article type: Research Paper

- Date text written or revised: June 07, 2014

- Abstract Word Count: 176

- Number of Figures: 6

- Number of Tables: 1

- Figure Captions Word Count: 93

- Text of Paper Word Count (without the above items): $\mathbf{6 2 8 8}$ including references and acknowledgements

\title{
Perceiving Urban Liveability in an Emerging Migrant City
}

\begin{abstract}
(176 words)
Gulf cities have witnessed rapid urban growth where new migrant communities from various cultural backgrounds have been evolving over the past two decades. This paper explores perceptions of liveable urban environments in Qatar's capital city, Doha. An attitude survey of 280 migrant professionals from different cultural backgrounds engaged in the high service sector was conducted. A profile for each cultural group including westerners, middle-easterners, Indians, Southeast Asians was developed to analyse the way in which key liveability factors are perceived. Factors were classified into two overarching categories: urban life and urban spaces. Urban life category included aspects that pertain to traffic and movement experience, residential satisfaction, shopping experience, and satisfactions of leisure and service spaces. Urban space category included attractiveness, iconicity, and familiarity, which were attitudinally explored in four public open spaces. The inquiry uncovers a number of concerns related traffic experience, housing quality, parking spaces, school facilities, and shopping opportunities. This may stymie the city's global attractiveness success on the global stage while warranting the need for addressing livability as part of future development plans.
\end{abstract}

\section{Keywords specific to this article}

Liveability; Multiculturalism, Doha; Sustainability; Migrant city 


\section{Introduction}

Gulf cities have witnessed rapid urban growth and a transformation of social and economic structures due adopting new development strategies. The vision to develop Gulf cities into global hubs is based on the fortunate geographic location between rising markets in combination with the still remaining wealth on fossil fuels in the region. The main pioneer of this new development model has been the Emirate of Dubai, which was the first to initiate a freehold property market stimulating an unprecedented construction boom at the beginning of the $21^{\text {st }}$ century. The direct consequence has been extensive immigration and a subsequently shrinking share of the local population to less than 15\% (Davidson, 2009). In most Gulf cities, the migrant backgrounds of mid-income to high income groups are rather diverse, while a large majority of low-income labourers were recruited from South Asian countries. Particularly, new economies within the emerging high service sector have been built on migrants from various origins leading to a multicultural society.

Taking Qatar's capital city Doha as an example, it was a fishing and pearl diving settlement. Today, it is home to more than $90 \%$ of the country's 2.0 million people, including over $80 \%$ foreign workers from other countries. Up to the mid-1960s, the majority of the buildings in Doha were traditional houses that presented local responses to the surrounding physical and socio-cultural conditions. During the 1970s, Doha was transformed into a modernized city. However, in the 1980s and early 1990s, the development process was slow compared to the preceding period due to a discouraging political atmosphere and the first Gulf war (Salama and Wiedmann, 2013-a). Since the end of the 1990s, the city has acquired a new geo-strategic importance. Through the shift of global economic

forces, it is being developed as a service hub, joining other major cities in the region and entering a fierce competition (Wiedmann, Salama and Thierstein, 2012). One key aspect to establish Doha as a regional centre of service sectors is however continuous immigration.

The multicultural aspect of a migrant, multicultural city is expected to have an increasing impact on future urban developments. Until today, little attention has, however, been paid to this aspect, including the understanding of the resulting inhabitants' spatial and lived experience and their attitudes toward the new urbanized spaces. This paper bases its argument in this regard on the premise that the global condition has created a sense of "placelessness" in many cities, and Doha is no exception (Salama, 2013-b). As a reaction, evoking a sense of place through creating urban diversity by introducing mixed-use developments and a wide variety of activities and fostering liveability and the quality of urban life have become primary concerns in contemporary discourse on urbanism (Fainstein, 2005). As in the case of many emerging cities worldwide, Doha's economic future will therefore heavily rely on its attractiveness as a residence for multicultural migrant communities. 
Developing competitive service sectors postulate that Gulf cities will increasingly rely on the longterm commitment of educated workforce to settle and subsequently to invest in Doha. The frequent exchange of migrant communities means a significant loss of knowledge as well as capital and thus great difficulties in establishing new economic sectors. In order to attract high-income groups, Doha should be perceived as a liveable place providing a wide range of urban qualities. This paper attempts to add important empirical research to the current struggle to gain insights into how attractive urban environments are perceived and experienced. Based on key theoretical underpinning a methodological approach is established to examine the various ways Doha is perceived by the four main cultural groups within the present mid-income migrant society. The paper is concluded with an outlook that articulates that major challenges to improve liveability in the city.

\section{Selected theoretical underpinnings on liveability}

Liveability is the totality of the features that add up to a group, a community, or a city's quality of urban life - including the built and natural environments, economic prosperity, social stability and equity, educational opportunity, and cultural, entertainment, and recreation possibilities (Partners for Liveable Communities, 2012). Most liveability definitions involve aspects related to effective transportation, community, and quality. Yet, there is no one-consensus definition.

Two important perceptive points must be made in the context of theorizing liveability. The first is that recent research reveals that there is a conceptual overlap between liveability and sustainability (Ministry of Environment New Zealand 2011). Industries and government agencies worldwide have addressed liveability as an important aspect of healthy cities (Philips Professional and Public Affairs, 2010). Nonetheless, a growing body of knowledge is emerging to support each separately. The second point posits that there is a clear distinction between "urban" and "built" where the former is about inhabitants, while the latter is about buildings. On the one hand, an "urban environment" is any street, neighbourhood, suburb, or city with enough people, typically more than a thousand. A "built environment" is one that has a high ratio of buildings and structures to open space, and where those buildings are used for a variety of activities (Chase, Crawford and Kaliski, 1999). In a recent comprehensive literature study on liveability and sustainability, commonalities emerged due to a lack of definitional distinction between the two terms. This underscores, however, the development of an interconnected relationship between both concepts (Young and Hermanson, 2013). Clearly, urban environments and built environments are the same thing - a high population requires a high density of buildings. This connotes that liveability involves duality; two major dimensions. The first is physical and relates to objective measures of the built environment, and the second is intangible and relates to subjective aspects that pertain to feelings and perceptions of the people living in that environment (Goonewardena, Kipfer, Milgrom and Schmid, 2008). 
With their varied socio-physical, socio-economic, socio-cultural, and socio-political presence, cities have always been highly differentiated spaces expressive of heterogeneity, diversity of activities, entertainment, excitement, and pleasure. They have been (and still are) melting pots for the formulation of and experimentation with new philosophies and religious and social practices (Glazer and Moynihan, 1963). Thus, the perception of the liveability of a city highly depends on the various backgrounds of inhabitants. Yet, a multifaceted view seems to dominate recent debates on liveability. Such a view involves common topics such as smart growth, complete streets, lifelong communities, context sensitive design and planning, transit-oriented development, and place making. While additional liveability premises exist, these most common topics represent those with the most established literature. Liveability is about pleasant and appropriate urban environments that offer and reflect cultural values and foster individual career aspirations. According to Shaftoe (2008), key principles integral to this aspect are equity, dignity, accessibility, conviviality, participation, and empowerment.

In the context of Gulf cities, liveability expresses the notion of a place that is good to live, work, and play in an urban environment where people enjoy a high quality of urban life based on their own perceptions. The term "liveable" is thus not limited to a strict set of certain qualities of an urban environment. It similarly applies to the degree to which diversity is achieved to enable inhabitants to identify and attach to places. This includes their satisfaction with the quality of urban life, the quality of their residence and movement within the city, among other issues. Any quality is however assessed by the individual based on past experiences and gained values. Thus, similarities how certain urban qualities are perceived can be detected in the case of a group of people who grew up in a comparable environment. Subsequently, the cultural background of immigrants plays an important role in to what extent emerging cities are perceived as liveable and thus attractive.

The work of the Henri Lefebvre has had a large impact on the contemporary understanding of space as a product of complex 'social superstructures' (Lefebvre, 1991, p. 85) arguing that space cannot be understood as a simple collection of elements because a society's space is actually a product that has been created through its own individual spatial practice and perception. Lefebvre introduced the term 'lived space' as the unconscious, non-verbal direct relation of humans to space. Also known as 'representational space', it is directly lived through associated images and symbols (Lefebvre 1991, p. 39). Thus rooted in the past experience it is essentially subjective wherein the outer physical space resonates with the inner imagination. Specific locations within a locality can become focal points due to their position and status within the representational space of the particular community of people who use that locale (Lefebvre, 1991, p. 45). Thus, the perception of 
liveability depends on this individual relationship between inhabitants and surrounding space (Purcell, 2002).

\section{A methodological framework: Examining liveability}

In order to explore the various perceptions of liveability in Doha a comprehensive survey was conducted by the authors in 2012-2013. It aimed to investigate key parameters that foster the development of insights into a better understanding of liveability. The investigation is exclusively focused on mainstream middle class expatriates and their perceptions due to their key role in introducing demand-driven incentives as consumers and investors. An attitude survey was distributed to employees in 43 companies within the advanced producer service sector in Doha. The companies were selected according to their key roles in current developments and their overall size. More than $70 \%$ of the selected companies have been in Doha less than ten years and have recruited mainly expatriates. Overall 351 employees participated in the survey and 280 complete responses were received.

Encompassing multiple-choice and open-ended questions the survey was constituted in three sections. The first was about basic information related to age, gender, country of origin, years of residency in Doha. The second concerned itself with urban life aspects such as mobility, housing, and city services. This section was analysed into "urban life perceptions" by comparing the responses of each cultural group. The third section aimed at exploring respondents' experience of key urban spaces in the city where questions were supported by photographs to establish an understanding of "urban space perceptions." Participants were given one month to fill in the questionnaire and were offered the opportunity to contact the authors for clarifying the questions as needed.

The initial step of the analysis involved an identification of four main groups of migrants with a comparable background: Middle Eastern, Western, Indian, and South-East Asian. Notably in this step, the cultural background is defined only by the country of origin of the participants based on the understanding that several sub-cultures may exist within a country. Therefore, the study assumes that most of the participants from one world region share a certain set of experiences and values. Overall, 280 survey forms were utilized for assessing and comparing results, with approximately 70 forms were selected to represent each group after the exclusion of incomplete questionnaires.

\subsection{General profile and cultural background of the survey participants}

Despite the fact that all participants work in the advanced economic sector the salaries often differ depending on education, experience and country of origin. In this context, a degree holder or an experienced professional from a Western country usually demand and is offered a higher salary. 
Thus, it can be assumed that participants who originate from Europe, North America or Australia earn a higher average salary or have entitlement to certain allowances. While around $76 \%$ of all Western Interviewees originate from Europe and mainly from the United Kingdom (49\%), the remaining share is constituted by North Americans (20\%) and Australians (4\%). The high average age of 39 years in the case of the Western respondents can be interpreted as a further indication that they occupy senior positions in companies identified. The female share of the respondents with an Indian background is lower when compared with the other three groups. The average number of years of residence in Qatar the Middle Eastern group as a whole is the highest (Table 1).

\begin{tabular}{lccccc}
$\begin{array}{l}\text { Cultural } \\
\text { Background }\end{array}$ & \multicolumn{2}{c}{ Gender } & $\begin{array}{c}\text { Average } \\
\text { Male }\end{array}$ & $\begin{array}{c}\text { Years in } \\
\text { Doha }\end{array}$ & $\begin{array}{c}\text { Car } \\
\text { Ownership }\end{array}$ \\
Indian & $81 \%$ & $19 \%$ & 35 & 8 & $73 \%$ \\
Middle-Eastern & $61 \%$ & $39 \%$ & 31 & 12 & $84 \%$ \\
South-East Asian & $44 \%$ & $56 \%$ & 35 & 4 & $46 \%$ \\
Western & $59 \%$ & $41 \%$ & 39 & 3 & $81 \%$
\end{tabular}

Table 1. Overview of the four main groups of survey participants.

The majority of the Middle Eastern survey respondents originate from the Levant including Lebanon $(39 \%)$, Syria $(13 \%)$ as well as Jordan $(11 \%)$ and Palestine $(11 \%)$. Egyptians constitute the remaining $26 \%$ of this cultural group. Their average age is the lowest of all the four groups although they have spent the longest time on average in Qatar. This is a clear indication that many Arab expatriates have decided to reside in Doha in parallel to or before the recent construction boom and that there is a general tendency of long-term commitment to the city. This can also be observed in the case of respondents from India, who have spent on average 8 years in Qatar. More than $94 \%$ of all Southeast Asian participants are from the Philippines, while only $6 \%$ are from Malaysia and Indonesia. In addition to their rather short average stay in Qatar the largest share of female respondents characterizes this group at $56 \%$, with the lowest rate of car ownership at only $46 \%$ for the whole group.

\subsection{Relocation motives and residential profile}

All participants were asked to assess their main motives of why they have relocated to Doha (Figure 1). Key parallels can be detected between Western and South-East Asian respondents, whose main motives are the job opportunity itself, the professional experience and higher salaries than in their countries of origin. In both cases cultural factors play no role at all, while family life and safety are perceived as minor motives. This is in clear contrast to participants from the Middle East, in which case all motives seem to play an equal important role, which can be interpreted for a clear 
indication that many of them are prepared to stay in Qatar long term. In the case of Indian migrants a large majority of respondents identifies safety as a major motive in addition to the high salary. Moreover, family life seems to play an equally important role within their motives to move to Doha.

Participants were requested to share their residence location as well as their residence type. More than half of the respondents (54\%) live in apartments in central urban areas followed by $38 \%$ who live in villas or apartments in gated residential communities in the urban periphery (Figure 2). The remaining share of $8 \%$ lives in exclusive residential towers along the Northern waterfront. Notably, a majority from Western countries (56\%) lives in the urban periphery, while only $26 \%$ live in central districts. For other groups most respondents live in apartments in the rather densely populated areas close by C-Ring Road, one of the major urban arteries in the city. Neither Indian nor SouthEast Asian resides in waterfront developments. Approximately, about $20 \%$ of the respondents within each group did not choose their own residence, which is provided by their employers.

\section{Perceiving Urban Life}

The urban life component aims at understanding how different groups perceive key liveability factors. Factors included traffic experience, residential quality, shopping experience, leisure, and the overall attractiveness of the city.

Participants were asked if they experience traffic in Doha as chaotic, moderate, or pleasant. A majority of those from Western origin (73\%) assesses the traffic conditions in Doha as chaotic. While only a slight majority of Middle Eastern respondents share the opinion that traffic experience is moderate $(55 \%)$, a majority of $66 \%$ and $79 \%$ perceives it as moderate and even pleasant in the case of Indian and South-East Asian respondents. Most respondents rely on their own cars, while the remaining share uses taxi services and personal drivers. When participants were asked if they would actually prefer public transportation instead of using a car or taxi due to climatic conditions more than $70 \%$ prefer to drive a car instead of using a bus service. Only in the case of migrants of Western origin a major share of $41 \%$ would rather use public transportation, which is likely based on their perception of traffic conditions as rather chaotic and their past experiences regarding the standards of public transportation in their home countries, especially Europeans. Public transportation services are not yet provided to all inhabitants and limited to a few bus routes.

Approximately $90 \%$ of all respondents are satisfied with their current residence, but in none of the four groups a majority can be found who would perceive their present housing conditions in Doha as an improvement to their former residence outside Qatar. In the case of respondents with a Western or Middle Eastern background only $20 \%$ experience their new residence as an improvement on their previous standard, while almost $40 \%$ of Indian and South-East Asian 
interviewees identify their housing conditions as a significant improvement. They were furthermore asked to share their experiences and perceptions regarding the situation of commercial services and leisure spaces in Doha. Shopping malls are currently the main centres for shopping as well as for entertainment in Qatar. Most interviewees share the preference of shopping malls instead of shopping streets in central areas due to weather temperatures and humidity as well as their accessibility by car. It is observed that old downtown areas are to a large extent avoided by most respondents. While around $50 \%$ of the South-East Asian and Middle Eastern survey participants visit the old city centre every month, around $64 \%$ and $52 \%$ of Western and Indian respondents visit it only a few times per year. While Middle Eastern and Western respondents mainly prefer to visit central areas in order to go to certain quality restaurants, a majority of Indian and South-East Asian participants visit downtown areas only to experience shopping. $50 \%$ of all interviewees within each group are satisfied with the current supply of commercial services in Doha.

Participants were asked how many hours per week they spend for leisure outside their residence. While $40 \%$ with a Middle Eastern or Western background usually spend more than 10 hours per week outside in shopping malls, hotels or public leisure spaces, less than $20 \%$ of the respondents with an Indian or South-East Asian background spend a similar amount of time outside. The main leisure spaces identified by the respondents are four major shopping malls, the old historic city core, the waterfront promenades as well as hotels. In contrast to the other three groups, a high percentage of Western participants prefer to spend their leisure time in hotels $(78 \%)$. While in the case of Middle Eastern survey participants a majority prefers to spend leisure time in restaurants in the old city core, South-East Asians and Indians clearly prefer shopping malls and public spaces, such as the Corniche/the waterfront or Aspire Park. In addition, Indian and South-East Asian respondents perceive the distances to leisure spaces as too far from their residences, while only around $25 \%$ of the survey participants share this perception in the case of the Middle Eastern and the Western groups. In all four groups a slight majority of around $58 \%$ assesses the existing leisure spaces as generally attractive.

Asking about their general impressions regarding the attractiveness of Doha as their city of residence a majority of respondents in all four groups can imagine residing in Doha long-term. While almost $90 \%$ of Middle Eastern respondents would like to settle in Doha more permanently, approximately $70 \%$ of all respondents in the other three groups would be interested to live in Qatar beyond their initial contracts. In order to assess the general impression of the city participants were asked how attractive they have perceived Doha on arrival and how they perceive it today. In the case of Middle Eastern interviewees no major difference can be assessed and a majority of approximately $70 \%$ shares the opinion that Doha is an attractive city. A significant shift between initial perception and current assessment can be noticed in the case of the other three groups, in 
which cases the share of a positive perception of Doha has increased from around $55 \%$ to more than $71 \%$. In addition, a large majority of respondents share the opinion that Doha will continue to become more and more attractive in future.

\section{Perceiving Urban Spaces}

In attempting to understand inhabitants' perceptions about key urban spaces or nodes within the city participants were asked to identify the most representative urban spaces in Doha. The most frequently mentioned urban space was the high-rise agglomeration in the West Bay viewed from the Corniche/waterfront. However, most respondents perceive the old historic market, known as Souq Waqif (the standing market), as most representative urban space. The Souq was restored between 2004 and 2007 and was shortlisted for the Aga Khan Award for Architecture. Other urban spaces including the exclusive residential areas with public access such as the Pearl development, and the Museum of Islamic Art were mentioned as important urban spaces representing contemporary Doha. In order to get a closer insight of how urban spaces are perceived by the participants, four urban spaces were identified to examine whether they would be perceived as familiar or unfamiliar, attractive or unattractive as well as iconic or subtle.

The first urban space was the Corniche/waterfront due to its dominance. The Corniche/waterfront was designed by the British architect Llewlyn Davis and built during the 1970 s on partially reclaimed land. The 7 kilometre long promenade links the old port area close by the historic city core and the new urban extension in the West Bay. Since the end of the 20th century West Bay became the main centre for high-rise projects in Doha, which was ignited by the announced move of public and semi-public institutions. In 2008 the Museum of Islamic Art, designed by the I.M. Pei, was completed on the opposite side of West Bay forming an ensemble of postmodern and traditionally inspired architectural landmarks (Salama and Wiedmann, 2013). Due to its size and position the Corniche/waterfront is often perceived as the main centre of Doha in spite of its prime function as transition zone. All four groups are very familiar with the Corniche/waterfront and in the case of each group a majority perceives this key urban space as attractive and iconic. Only in the case of the South-East Asian group a significant share of respondents of $33 \%$ would not identify the Corniche/waterfront as iconic and around $20 \%$ do not perceive it as attractive (Figure 3). Reasons could be the very limited availability of commercial services and the constrained accessibility for pedestrians due to the insufficient traffic lights and crossing points. Nonetheless, in spite of the fact that the high-rise waterfront has only been constructed a few years past, it has become the main landmark representing modern and globalized Doha in the view of all cultural groups.

The restored historic market area was the second urban space examined (Figure 4). In addition to the Souq Waqif, the historic part of Doha is currently regenerated by a major development, known 
as Msheireb. Today the rebuilt traditional market is the only urban space where the historic vernacular architecture can be experienced. Most respondents are familiar with the urban area due to frequent visits. Southeast Asian respondents are however the least familiar with the urban area at only 64\%, while Middle Eastern respondents are the most familiar with it. Most Southeast Asians furthermore identify the historic core as neither very attractive nor iconic, while all other groups share the perception that it is very important for Doha as an attractive and iconic urban space representing the heritage of the city. In particular, Europeans perceive the Souq Waqif as an iconic landmark of Doha due to their general widespread idea of a historic core reflecting the main identity of a city.

The C-Ring Road along the Al Sadd district was selected as third key urban space (Figure 5). The ring road encircles the old downtown area and in recent years it became the main centre for office developments as well as apartment buildings. Due to the extending urban periphery the Al Sadd district became one of the most accessible and increasingly important business districts. Today a majority of companies are currently located in the area and its surroundings. Thus, most respondents reside in apartments within or close by the Al Sadd district. Due to the previous restrictions on low-rise residential developments along C-Ring Road, the recent transformation to a high density and mixed-use urban area has led to a rather fragmented urban structure. Thus, only a minority of respondents within each group would perceive this urban space as attractive or iconic. Particularly, respondents with a Western background assess the space as unattractive and rather unfamiliar due to its chaotic structure, while Middle Eastern and Indian survey participants are highly familiar with the environment and are generally rather neutral when they assess its attractiveness. Southeast Asian participants are less familiar with the spatial configuration but similarly neutral.

Participants assessed the particular urban landscape in the suburbs, which is defined by residential areas mainly occupied by locals, compound developments and large-scale shopping malls. Today more than $60 \%$ of the overall urban area is covered by these urban typologies. The most prominent areas can be found in the North and West of the city. Similar to the case of Al Sadd urban space a majority of participants is housed in compounds in these urban areas. Due to the high walls protecting the privacy of Qatari families and compounds and due to a missing supply of proper pedestrian walkways, public spaces or integrated services, the urban periphery of Doha is currently perceived as rather unfamiliar and unattractive. Participants with a Western background are mostly repelled by the current built environment in Doha's suburbs, while Middle Eastern interviewees perceive the urban space of these areas as less conflicted and mainly neutral. A substantial majority of Indian and Southeast Asian respondents are not familiar with this urban setting and perceive it as rather unattractive (Figure 6). The negative perceptions are mainly based on the 
missing street life and the rather deserted public spaces in suburban areas as well as the general impression of rejection and introverted privacy as well as the often missing pedestrian walkways.

The comparison of the four urban spaces reveals the fragmented nature of City's peripheries that are currently perceived as less attractive. While key landmark urban spaces, such as the Corniche/waterfront, shape an impressive image of Doha as an emerging international and modern metropolis, the actual everyday urban environment of most respondents in suburban and downtown areas differs dramatically from this designed urban stage. The rapid urban growth coupled with missing regulations led to fragmented and chaotic urban landscapes with hardly any distinct characteristics. Despite fact that the dense built environment of central areas is in clear contrast to the low-rise urban sprawl along Doha's periphery, both urban landscapes are an expression of randomness and supply-driven mechanisms within local real-estate markets. Doha is therefore an archetypal case of a late $20^{\text {th }}$ century-born city in the Global South in which key spaces are overemphasized in order to brand a city with a globalized image, while most urban areas are replaceable, repetitive and repelling (Brenner and Roger, 2011).

\section{Lessons and Challenges: Toward a Liveable Doha}

The inquiry into liveability and its underlying factors uncovers a number of concerns and alarming figures. Traffic experience appears unsatisfactory, and low quality housing construction and maintenance and insufficient parking spaces, school facilities, and shopping opportunities are major sources of discontent for the majority of respondents. Today, the continuous exchange of migrants hinders the demands of communities from having a more efficient impact on development patterns. It should be noted nonetheless that life in Doha is often still perceived as attractive due to high salaries, general safety and many professional opportunities in certain areas, such as construction, research and education (Nagy, 2006).

While this research involves investigations of liveability perceptions as they relate to middle and upper middle class expatriates other segments of Doha's society including the labour class are not included. In essence, this represents one of the limitations of this exploration. However, it generates a discussion on social sustainability and the challenges involved in achieving the balance between actual demands and current supply of urban environments. Doha's society is facing the consequences of the large-scale inflow of an expatriate and migrant labour workforce over a short period of time. This large population segment of expatriate workers is in addition to skilled or professional med-income and high-income expatriate groups engaged in newly emerging economic sectors. The various cultural differences, as well as the widely diverging income brackets, have led to strong social segregation. 
Based on the fact that the local population is a small minority of approximately 13 per cent of the total population, there is no coherent majority within Doha's society apart from the diverse groups of expatriates. Segregation patterns between nationals and expatriates are zealously maintained; furthermore, constraints to developing a less anonymous and more integrated society are also due to the continuous labour movement patterns and exchange of a large percentage of the expatriate workforce on a regular basis. In addition to social segregation by residential area, little effort, coupled with a lack of desire, has been made by decision-makers to develop more integrated environments and public realms to be used as platforms for an emerging society. Today, while shopping malls are the most frequently used leisure and entertainment spaces for higher income groups, low-income groups usually shop and stay close to their residences, a clear indication of social and income demarcation which extends beyond residential patterns.

While future development plans of the city may seem to address specific groups and cater to specific age groups or cultural backgrounds, a more inclusive approach to the design of urban spaces presents a challenge. Urban design as a discipline and a profession focuses on creating environments that promote opportunities and experiences for all city inhabitants. Therefore, it is crucial that most of the urban space actions and activities are made available to and enjoyed by the majority of the city's population. In this respect, the lesson learned is that the urban development process of the city necessitates a consideration of the development of spaces based on the perception and understanding of different groups. This needs to be adopted as one of the key factors in developing liveable urban spaces that involve a wide spectrum of urban and spatial qualities relevant to the multicultural nature that characterizes such a globalizing context.

\section{Conclusion}

Often oversimplified the perception of a majority of mid-income inhabitants regarding the city as being a familiar and highly attractive place is an increasingly essential factor for the inner consolidation and thus sustainability of a city in the age of rapid globalization. Only a society with a shared level of identification to its environment can take responsibility for it. Today, the immense social segregation between social groups in Doha is not experienced as a very grave potential threat to stability. The images created in contemporary Doha are, however, fragile due to their superficial nature. Thus, creating identity is not only the challenge of city-branding strategies. Identity is to a large extent created when inhabitants can become active participants in the spatial development process rather than excluded observers. This goes along contemporary literature on urban identity (Lalli, 1992; Oktay, 2002; Sutton \& Kemp, 2011) which asserts that urban identity is a constituent of urban liveability and an integral component in the process of creating liveable environments in changing contexts. Therefore, one of the major challenges is to integrate migrant 
communities in the development of future Doha while sustaining Qatar's distinct local cultural identity despite the overall shrinking share of the native population.

The continuous exchange and movement of a majority of a fairly transient population exacerbate this situation of a conflicted identity. As such, Doha's contemporary society consists of several parallel societies as well as fragmented and often-isolated social groups, leading to anonymity and in some work situations, such as those of domestic helpers, isolation. Many Qataris feel threatened by this constant influx of people who they often feel are invading and changing their local culture. Thus, both future migration patterns and the willingness of the native population to adapt to the new situation of continuous internationalisation will therefore play a key role in shaping Qatar's new identity.

This study therefore contributes to the international and regional research efforts to understand urbanism in the Gulf region, as exemplified in Doha, and the potential impact of rapid and extensive migration. The newly emerging Gulf cities have attracted a rather diverse mixture of cultural groups, who share their one main common interest to earn higher salaries than in their home countries. This effect of the globalization process has however led to replaceable urban landscapes accommodating the urgent needs of consumption rather than integrating and reflecting cultural diversity. Exploring the perceptions of migrant communities can become the basis of further indepth research regarding the various potentials of how new demand-driven mechanisms, e.g. within housing markets, can diversify spatial developments in future. Thus, the outcomes of this study can be regarded as a first attempt to point out the potential key role of the various migrant communities in shaping a new urban identity in Qatar by investigating current perceptions of different cultural groups.

\section{Acknowledgements}

The material of this paper is part of a 3 years research project funded by Qatar National Research Fund (QNRF/NPRP 09-1083-6-023). Thanks are due to Fatma Khalfani, Ahood Al-Maimani, Velina Mirincheva for their support in conducting the survey.

\section{References}

Adham K (2008) Rediscovering the Island: Doha's Urbanity from Pearls to Spectacle. In The Evolving Arab City (Elsheshtawy Y ((ed.)). Routledge, New York, pp. 218-257.

Brenner N and Roger K (2011) From Global Cities to Globalized Urbanization. In The City Reader (LeGates RT and Stout F ((eds.)). Routledge, New York, pp. 599-608.

Chase J, Crawford M and Kaliski J (1999) Everyday Urbanism. The Monacelli Press, New York. 
Davidson C (2009) Dubai: The Vulnerability of Success. Hurst C \& Co, New York.

Fainstein, SS (2005) Cities and Diversity: Should We Want It? Should We Plan for It? In Urban Affairs Review 42(1): 3-19.

Glazer N and Moynihan DP (1963) Beyond the melting pot: the Negroes, Puerto Ricans, Jews, Italians, and Irish of New York City. MIT Press, Cambridge.

Goonewardena K, Kipfer S, Milgrom R and Schmid C (2008) Space, Difference, Everyday Life: Reading Henri Lefebvre. Routledge, New York.

Lalli, M (1992) Urban-related identity: Theory, measurement, and empirical findings. Journal of Environmental Psychology 12(4): 285-303.

Lefebvre H (1991) The Production of Space. Blackwell, Oxford.

Ministry for the Environment - New Zealand (2011) What is a Liveable

Environment? http://www.mfe.govt.nz/publications/rma/live-work-play-

jun02/information/liveable.html (Accessed August 9, 2013).

Nagy S (2006) Making Room for Migrants, Making Sense of Difference: Spatial and Ideological Expression of Social Diversity in Urban Qatar. In Urban Studies 43: 119-137.

Oktay, D (2002) The quest for urban identity in the changing context of the city: Northern Cyprus. Cities 19(4): 261-271.

Partners for Liveable Communities (2012) What is Liveability? http://livable.org/about-us/what-islivability (Accessed September 17, 2013).

Philips Professional and Public Affairs (2010) Liveable Cities-health and well being in the urban environment, Philips Publications.

Purcell M (2002) Excavating Lefebvre: The right to the city and its urban politics of the inhabitant. In GeoJournal 58: 99-108.

Salama AM, Wiedmann F and Thierstein A (2012) People and the city: Unveiling the lived urban environment of Doha. In Bloomsbury Qatar Foundation Journals (http://dx.doi.org/10.5339/qfarf.2012.ahp36), Doha.

Salama AM and Wiedmann F (2013-a) Demystifying Doha: On Architecture and Urbanism in an Emerging City. Ashgate Publishing Ltd., Surrey.

Salama AM and Wiedmann F (2013-b) The Production of Urban Qualities in the Emerging City of Doha: Urban Space Diversity as a Case for Investigating the 'Lived Space'. Archnet-IJARInternational Journal of Architectural Research 7(2): 160-172.

Shaftoe H (2008) Convivial Urban Spaces: Creating Effective Public Places. Earthscan, London.

Sutton SE and Kemp SP (eds.) (2011) The Paradox of Urban Space: Inequality and Transformation in Marginalized Communities. Palgrave Macmillan, New York.

Young E and Hermanson V (2013) Livability Literature Review: Synthesis of Current Practice. In Transportation Research Board 92nd Annual Meeting (No. 13-2940). 
Wiedmann F, Salama AM and Thierstein A (2012) Urban Evolution of the City of Doha: An Investigation Into the Impact of Economic Transformations on Urban Structures. JFA/METU: Journal of the Faculty of Architecture 29(2): 35-61.

\section{Figure Captions:}

Figure 1. The main motives of the four groups to move and stay in Doha

Figure 2. The three main locations of residences and the share of each group

Figure 3. The waterfront promenade along the Corniche and the perceptions of the four groups

Figure 4. The restored historic city core and the perceptions of the four groups

Figure 5. The AI Sadd District along C-Ring Road and the perceptions of the four groups

Figure 6. The suburban landscape in the North of Doha and the perceptions of the four groups 

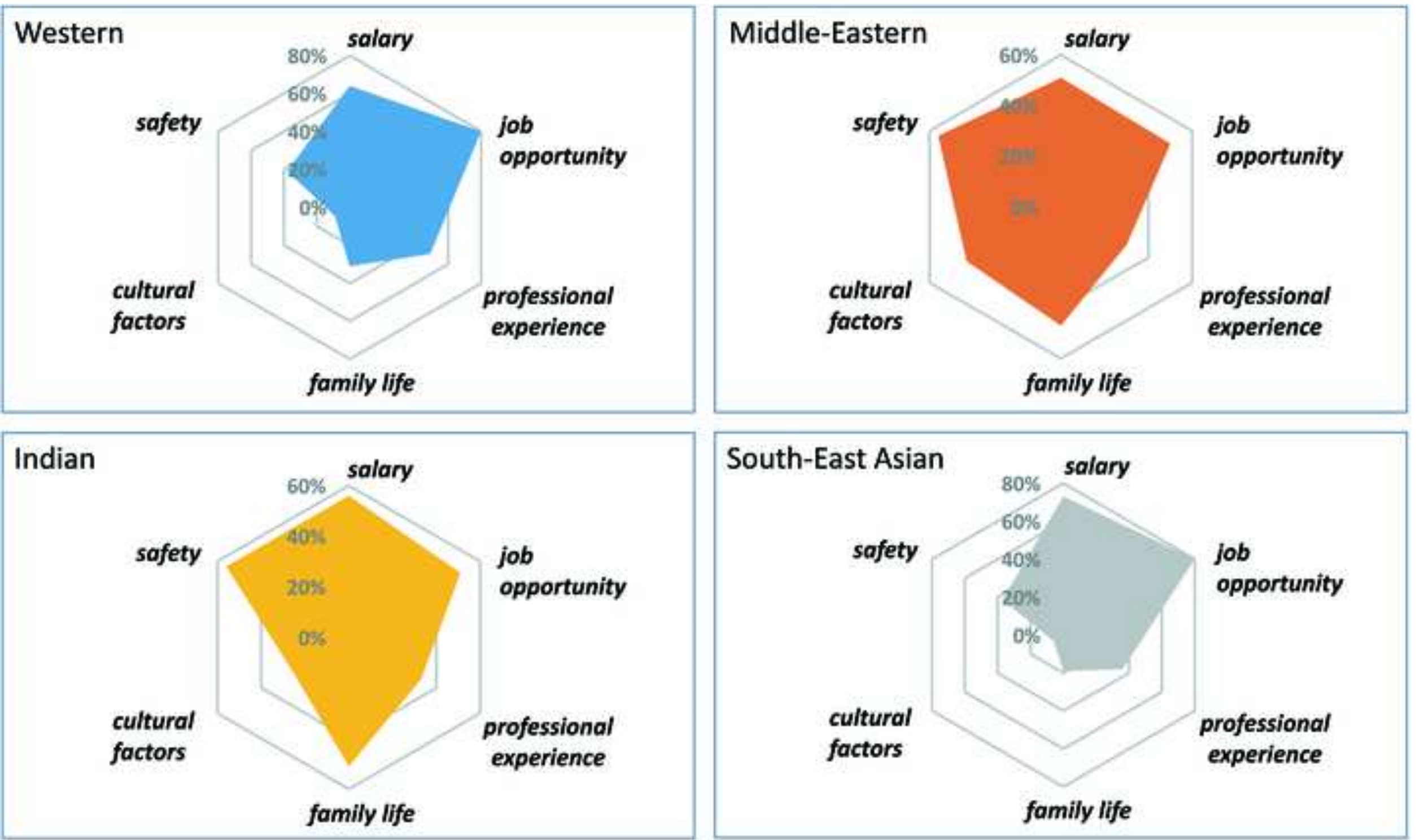


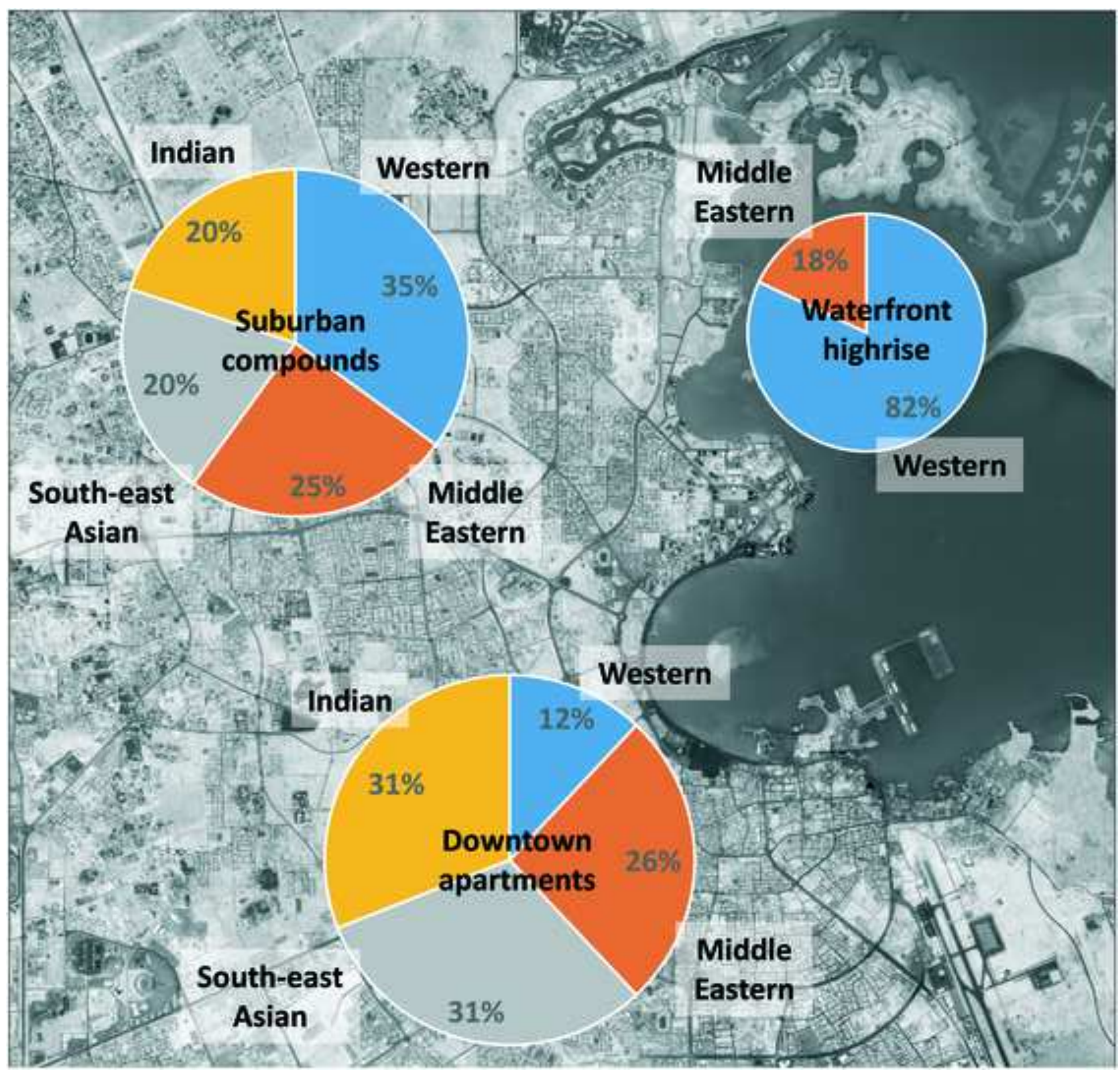



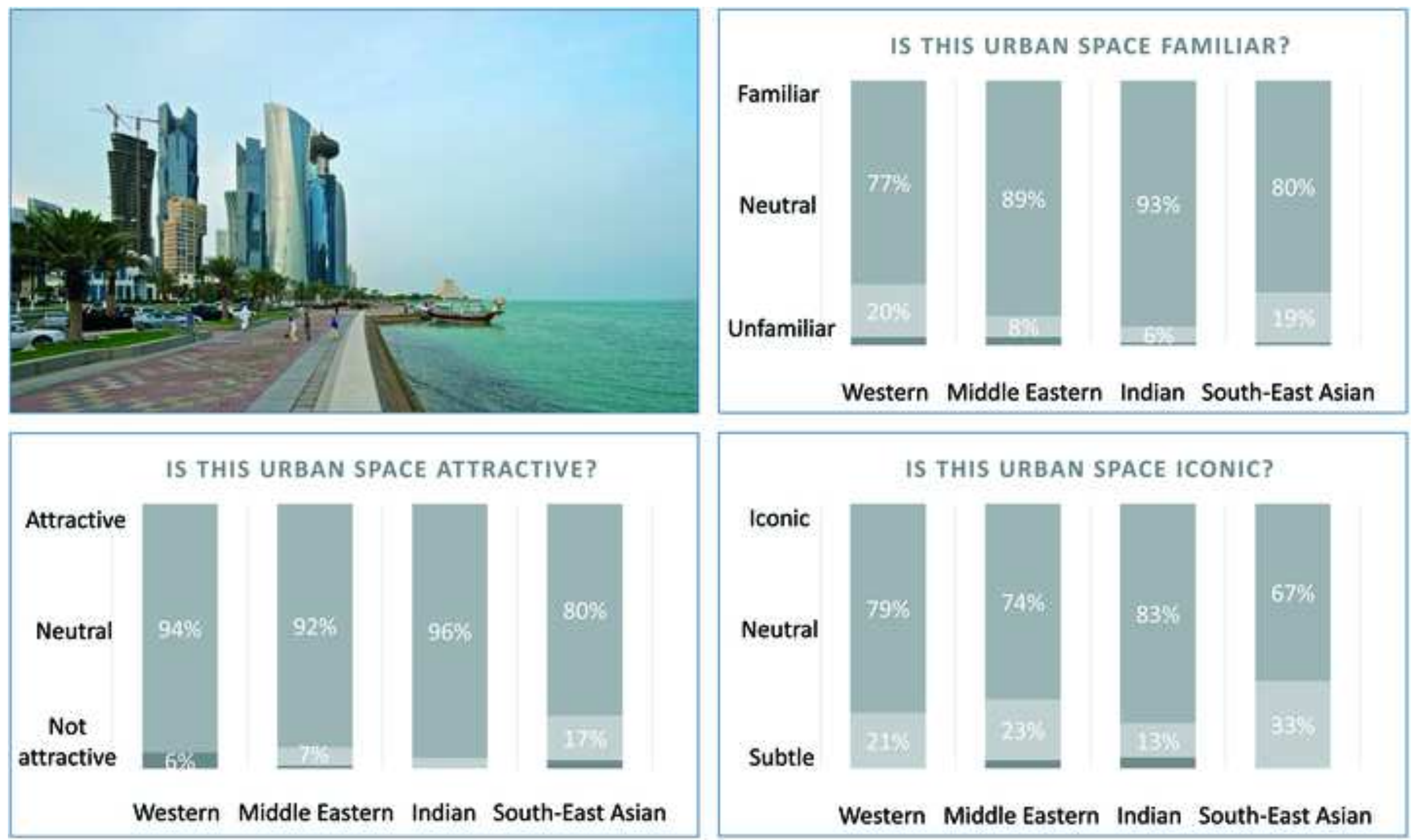

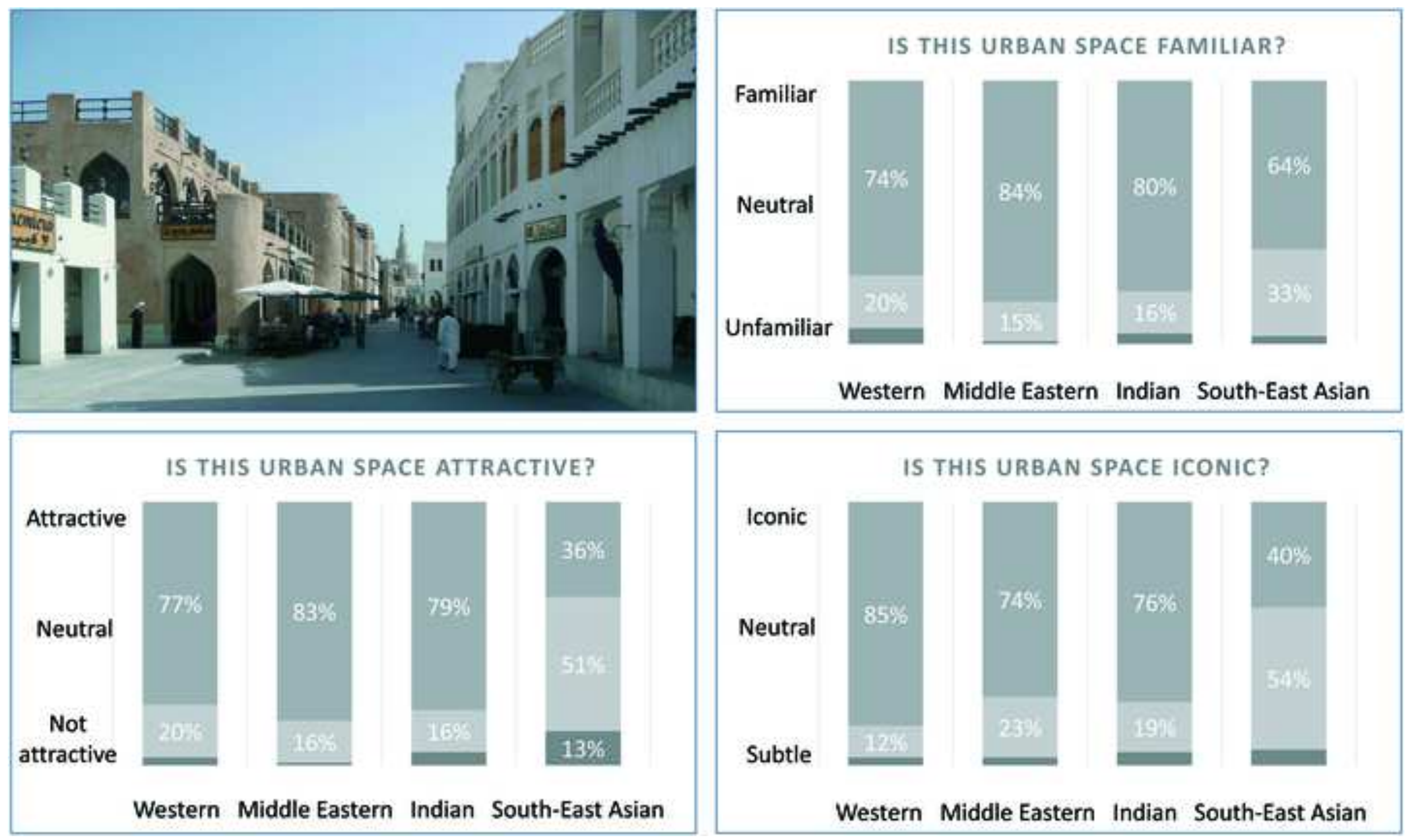

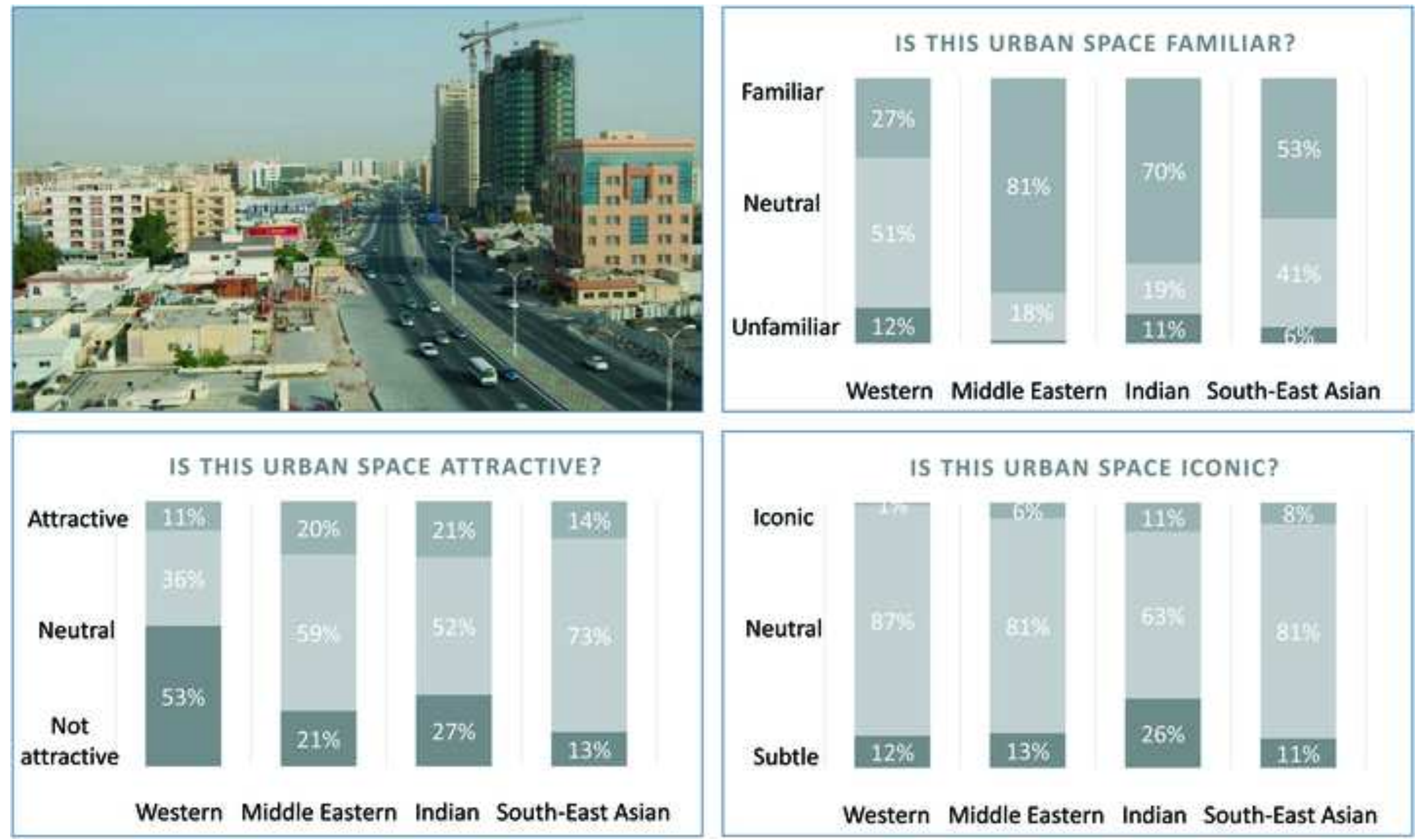

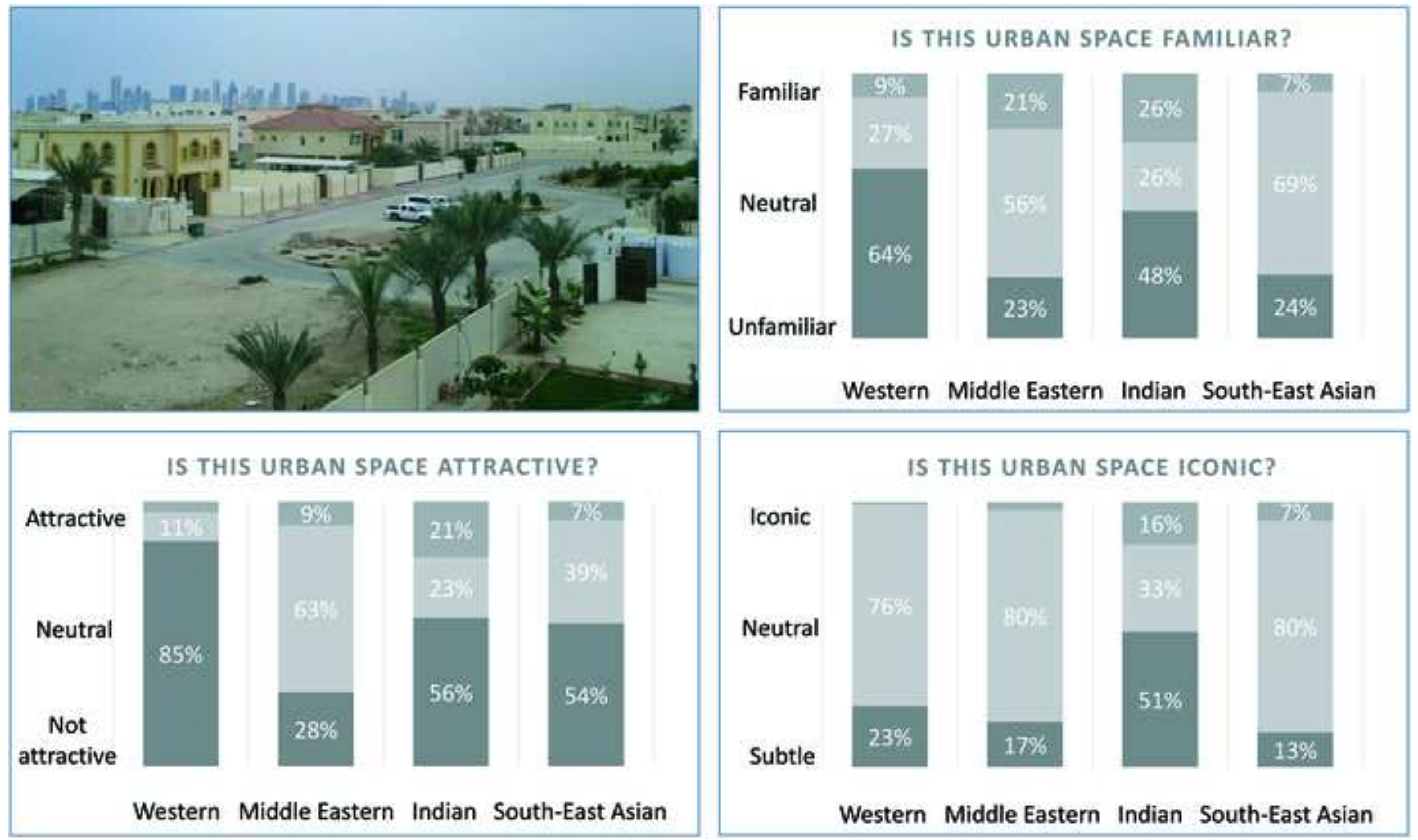


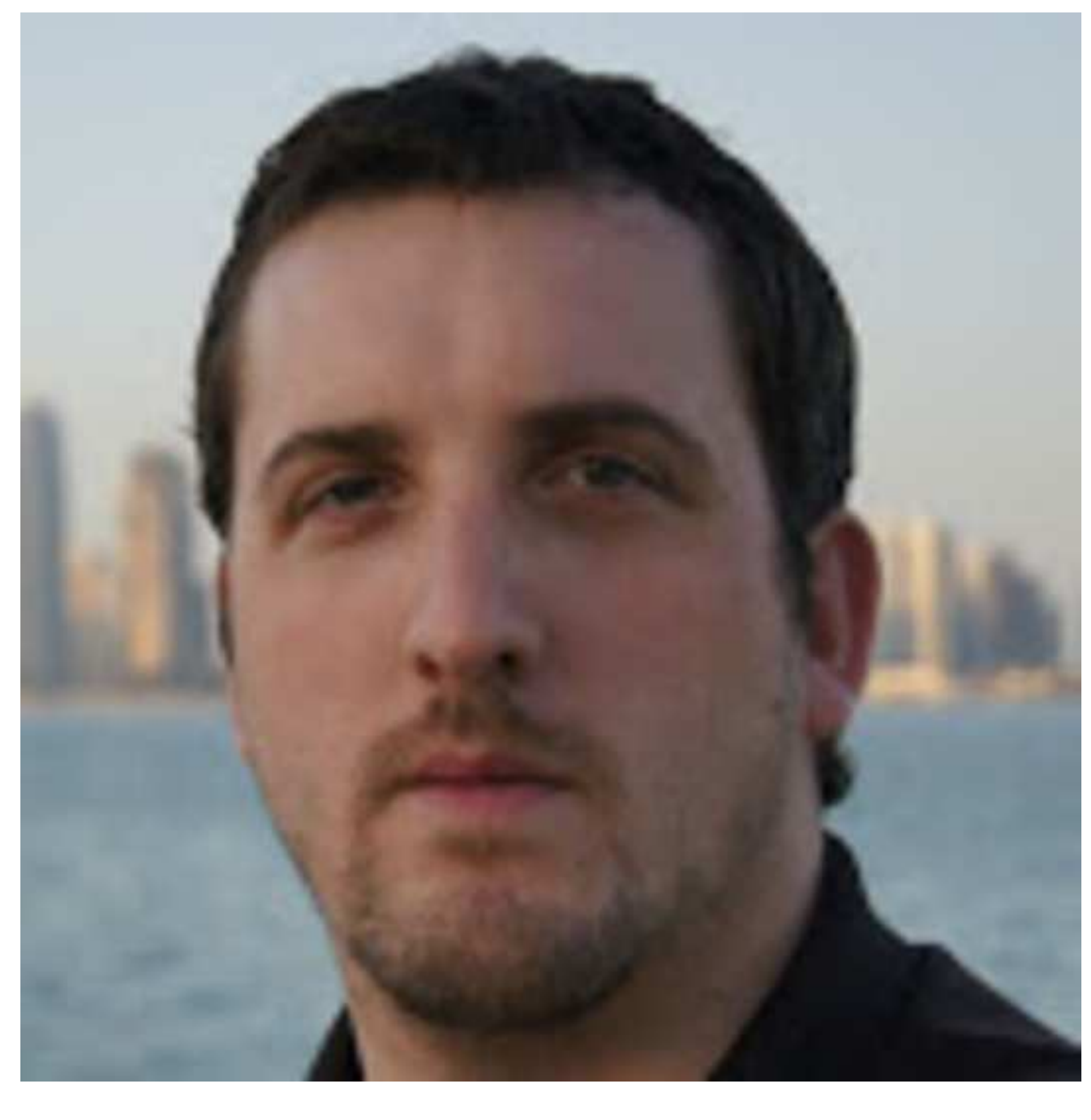

(

.
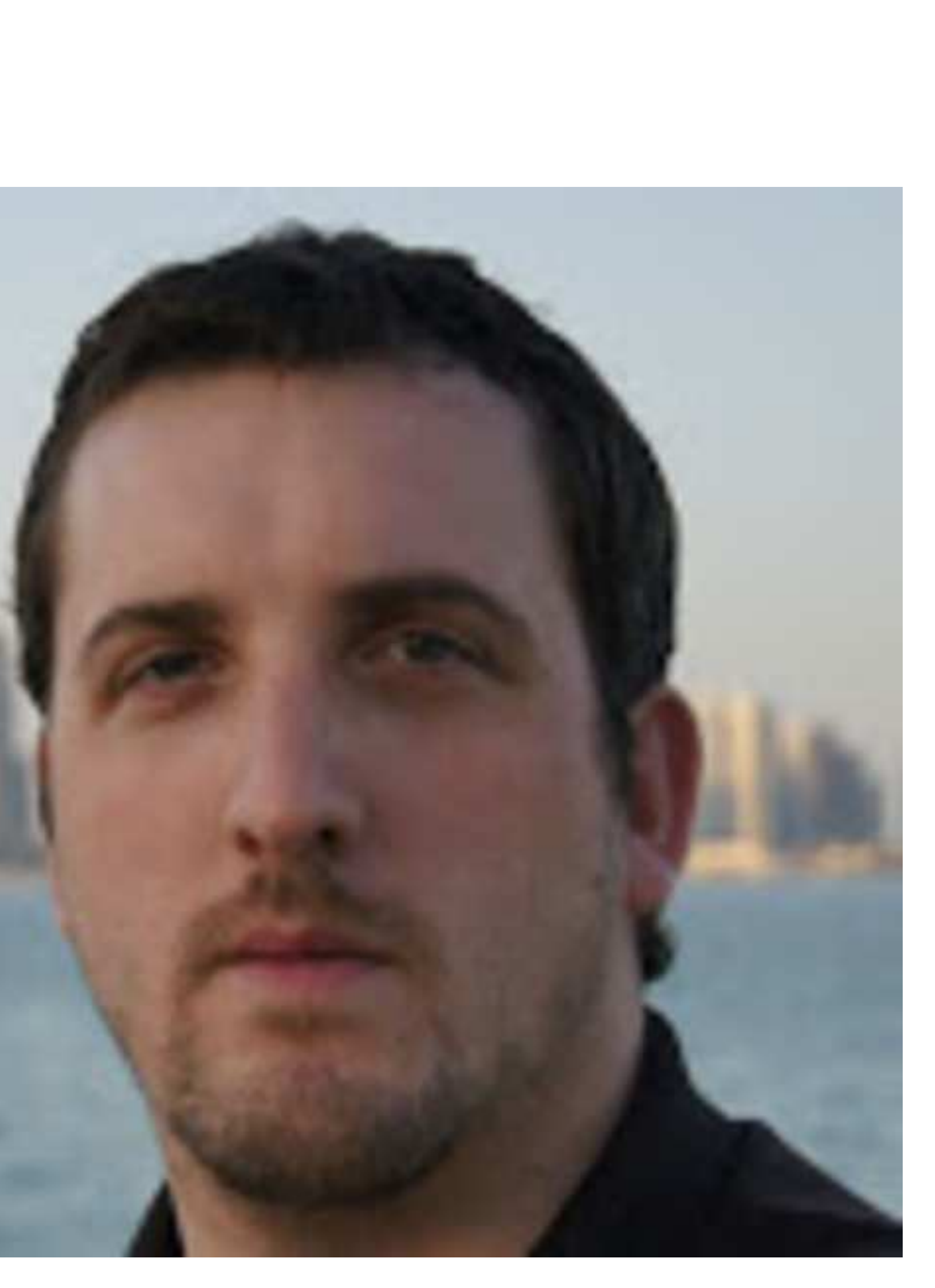
Please note that the reviewers' comments were in essence similar in terms of requesting a subdivision of the cultural groups. The authors have done their best to address this comment.

As well, one of the reviewers below indicated that enough text should associate the figures - The authors have addressed this comment thoroughly to offer more clarifications.

One reviewer together with UDP assessor requested the addition of a conclusion/conclusive statement and relate to the theme of this special issue. The authors have addressed this comment by adding a conclusion that reflects on material presented in the body of the paper while relating this to the notion of globalization and identity (from the perspective of livability and the presence of multi-cultural groups).

Please note that all added text has been highlighted in the new version of the paper.

We thank the editor for an excellent review process and hope this final version of the paper rises to the expectation.

Regards, Ashraf Salama (First Author).

Reviewer \#1: As many Middle-Eastern cities are developing in a highly competitive and fast manner, this paper offers a very timely insight into the importance of user experiences. It is such experiences that will determine the ultimate success of such urban developments. The paper is very well-written with a lucid focus. The range of multicultural groups surveyed is vital as well as critical. The theoretical approach, methodology, and analysis of the results are clearly presented. The paper addresses a key issue and will no doubt receive a wide readership.

The only minor suggestion would be to expand on, if possible, on the internal variability of each cultural group. There is indeed a mention of it in the paper, but it would strengthen the paper if elaborated a bit more. For example, does someone prefer/regard as neutral the 'urban chaos', not because of their cultural background but because they come from an urban neighborhood in their home country, hence the 'chaos' may be a fond or nostalgic recall (similar to place attachment) of their hometown. This could pan across the four cultural groups surveyed. For example, someone from New York and another from Mumbai may have such positive attractions to high traffic (vs. relatively emptier roads), because high traffic may remind them of a familiar image of home. In this regard, the concept of 'familiarity' can be elaborated more.

I highly recommend the publication of this paper!

Reviewer \#2: The paper is very well structured and the argument made by the author is very interesting. It is supported by a rich theoretical background that explicates a better understanding of the term "livability." The paper recognizes the diverse social structure of Doha. It highlights the 
importance of urban quality and livability in making a global city like Doha capable to compete in the new world order.

My only concern is the scale of the survey and the categories used to sort the results. For example, the "Middle East" category covers very diverse group of people with different backgrounds and motives of coming to Doha. Same applies on the category titled "Westerns." I suggest a brief comparison between more specific groups that represent major migrant communities in the city such as Egyptians verses Filipinos.

Reviewer \#3: This is a very valuable paper seeking the impacts of new rapid developments of Qatar and its socio-cultural effects on the previously intact society. The theoretical foundations of the paper are well underpinned by the seminal literature of liveable cities and the methodological approach, in terms of structure of the survey (which builds upon well recognised factors and variables of liveable cities), sampling strategies, approach to analysis etc., is robust and defensible. The presentation and the quality of English language is also outstanding. All these make this paper valuable and potentially suitable for publication in UDP.

Despite all merits mentioned above, this reviewer believes that the paper needs some minor revisions in order to make it clearer for the readers. One main issue is that, the results could be explained with more detail. Figures 1-6 contain invaluable facts, but these are not presented with enough details in the text. In other words, there is too much reliance on the graphical representation of the figures. I believe that each figure needs additional few sentences in order to represent the thoughts of the author(s) more clearly. This can mainly be done with emphasis on the interpretation of author(s) from the statistical facts, or where appropriate linking these to the seminal literature.

I also believe that a formal conclusion section is missing in this article. Although the author(s) have discussed the implications of the results in each respective section in a very scholarly way, a conclusion section could really help to showcase the author(s) more high-level thoughts about the findings, impacts, benefits and contributions of the study, and need for future research.

Assessor: This is a very valuable paper seeking the impacts of new rapid developments of Qatar and its socio-cultural effects on the previously intact society. The paper is very well written, clearly structured, and has a strong theoretical foundation. All these make this paper suitable for publication in UDP in general. However, it is believed that the quality of the paper will be higher if the comments by the referees are taken into consideration. In addition, in order to better match with the theme of the special issue ("Urban Identity in the Era of Globalisation"), creating links with the theme urban identity (at least in the conclusion section) is highly recommended. 